\title{
Multiple Response Optimization of High Temperature, Low Time Aqueous Extraction Process of Phenolic Compounds from Grape Byproducts
}

\author{
Hiba N. Rajha, ${ }^{1,2}$, Nicolas Louka', Nada El Darra', Zeina Hobaika ${ }^{1}$, Nadia Boussetta ${ }^{2}$, \\ Eugène Vorobiev ${ }^{2}$, Richard G. Maroun ${ }^{1^{*}}$ \\ ${ }^{1}$ Centre d'Analyses et de Recherche, UR TVA, Faculté des Sciences, Université Saint-Joseph de Beyrouth, Lebanon; ${ }^{2}$ UTC/ESCOM, \\ EA 4297 TIMR, Département de Génie des Procédés Industriels, Laboratoire Transformations Intégrées de la Matière Renouvelable, \\ Université de Technologie de Compiègne, Centre de Recherche de Royallieu, Compiègne, France. \\ Email: ichard.maroun@usj.edu.lb
}

Received November $19^{\text {th }}, 2013$; revised December $19^{\text {th }}, 2013$; accepted December $26^{\text {th }}, 2013$

Copyright (C) 2014 Hiba N. Rajha et al. This is an open access article distributed under the Creative Commons Attribution License, which permits unrestricted use, distribution, and reproduction in any medium, provided the original work is properly cited. In accordance of the Creative Commons Attribution License all Copyrights (C) 2014 are reserved for SCIRP and the owner of the intellectual property Hiba N. Rajha et al. All Copyright (C) 2014 are guarded by law and by SCIRP as a guardian.

\section{ABSTRACT}

In this study phenolic compounds extraction from grape byproducts was conducted using pure water as a solvent. High temperatures and low time incubation periods were used in the aim of reducing the cost of the process and heightening the phenolic compounds yield. Response surface methodology (RSM) was realized to study the effect of time and temperature on crushed and uncrushed grape pomace. The phenolic content was evaluated considering the quantity (total phenolics (TPC), flavonoids (FC), total monomeric anthocyanins (TMA) and tannins (TC)), and quality (antiradical activity (AA) and antioxidant capacity (AC)) of the extracts. High temperature low time extraction design used in this study was compared to the extraction process at moderate temperatures with relatively long periods of time. This was proved to ameliorate the quantitative extraction of phenolic compounds from grape pomace without affecting their bioactivity. Moreover, multiple response optimization showed the optimal extraction parameters to be $81^{\circ} \mathrm{C}$ and 140 minutes for the unmilled pomace samples, and $88^{\circ} \mathrm{C}$ and 5 minutes for the milled. TPC, FC, TMA, TC, AA and AC are almost the same for both optimums. Thus the possibility of replacing the milling process by the extraction time prolongation (for the unmilled pomace) of 135 minutes seems to be very plausible. HPLC analysis showed different quantity and diversity of extracted phenolics for the optimums. However this difference did not significantly affect the overall activity, showing that PC in the different extracts act in complete synergy all together leading to important biological properties. The obtained results using the extraction strategy adopted in this work could lead to several industrial applications.

\section{KEYWORDS}

Phenolic Compounds; Grape Byproducts; Optimization; Aqueous Extraction; Response Surface Methodology

\section{Introduction}

Arising from the winemaking process, grape byproducts are attracting an increased interest by reason of commercial motives and environmental concerns [1,2]. Grape pomace is highly rich in health beneficial phenolic compounds. These have several pharmaceutical and nutritional applications [3-7]. At an environmental level,

"Corresponding author. problems related to grape pomace disposal could emerge when burying these byproducts since this could affect the soil and the groundwater quality [8], the flora and fauna. When used as fertilizers, they even might prevent germination properties [9]. Consequently, the valorization of those byproducts reduces wastes and permits the purification of added-value products [2,10,11]. The isolation of food matrix retained compounds is commonly realized in food industries by different extraction processes [12], 
through the enhancement of the quantity and quality of the desired component [9]. Many factors are likely to affect an extraction process; therefore the optimization of the process seems necessary. Response Surface Methodology (RSM), firstly described by Box and Wilson in 1951 [13], is an efficient assemblage of statistical and mathematical methods for the progress and optimization of extraction processes [14]. This work comes to complete our previous work conducted by Rajha et al. 2013 [15], in which the extraction of phenolic compounds from grape byproducts was conducted at moderate temperatures with relatively long incubation times. Here, the solid liquid extraction of phenolic compounds from grape byproducts was studied with aqueous solvent through shortening the extraction time and heightening the incubation temperature. The possibility of substituting moderate temperatures with high temperatures at low duration, without affecting the quality of the extracts was the major target of our study. Thus, we have determined the extraction conditions capable of producing the same yield and quality of phenolic compounds, avoiding the highly energetic and costly milling process of the raw material by using uncrushed grape pomace. This work suggests an alternative low cost and environment friendly industrial extraction method, giving up organic solvent and milling process and shortening the extraction time.

\section{Materials and Methods}

\subsection{Sample Preparation}

The Cabernet Sauvignon grape byproducts were provided by château KSARA (Beqaa Valley, Lebanon). On arrival the raw material was stored at $-20^{\circ} \mathrm{C}$ until utilization. Defrosted at room temperature, the grape byproducts were either used unmilled or reduced to a particle size of $2 \mathrm{~mm}$. The aqueous phenolic compounds extraction process was done with a solid/liquid ratio of 1:4 $(\mathrm{w} / \mathrm{v})$. The fixed particle size and solid/liquid ratio were chosen based on the work of Spigno et al. 2007 [16]. After the solid-liquid extraction process with the heated solvent and under agitation, solids were separated by filtration [17]. The dry matter content in the grape pomace was $67 \pm 0.9 \%$.

\subsection{Total Phenolic Compounds Determination (TPC)}

According to the Folin-Ciocalteu method previously described by Slinkard and Singleton 1977 [18], an aliquot of $10 \mu \mathrm{L}$ of the sample solution was mixed with $100 \mu \mathrm{L}$ of commercial Folin-Ciocalteu reagent and $1580 \mu \mathrm{L}$ of water. After a brief incubation at room temperature (5 $\min$ ), $300 \mu \mathrm{L}$ of saturated sodium carbonate was added. The color generated was read after $2 \mathrm{hr}$ at room temper- ature at $760 \mathrm{~nm}$ using a UV-Vis spectrophotometer (UV9200, BioTECH Engineering Management, UK). The correlation between the absorbance and gallic acid concentrations creates a calibration standard curve. The Phenolic Compounds Concentration (PCC) of the samples was expressed as gallic acid equivalent $(\mathrm{mg} / \mathrm{L})$. Phenolic Compounds Yield (PCY) derived from these values was given by transforming milligrams of Gallic Acid Equivalent (GAE) per liter (mg GAE/L) into grams of GAE per $100 \mathrm{~g}$ of grape dry matter (g GAE/100g DM).

\subsection{Flavonoid Content (FC)}

The indirect method of flavonoid determination was performed as described by Ough and Amerine [19], through the precipitation of those compounds by formaldehyde. Five milliliters of aqueous solution of hydrochloric acid $1: 4$, and $5 \mathrm{~mL}$ of formaldehyde $37 \%$ were added to 10 $\mathrm{mL}$ of the sample. The sample was filtered after a 24 hour standstill period, and used for the non-flavonoid content determination by Folin-Ciocalteu method. The difference between the total phenolic and the non-flavonoid contents results in the calculation of the flavonoid content expressed as gallic acid equivalents $(\mathrm{mg} / \mathrm{L})$. Then the Flavonoid Content yield (FC) was calculated by transforming milligrams of Gallic Acid Equivalent (GAE) per liter (mg GAE/L) into grams of GAE per $100 \mathrm{~g}$ of grape dry matter (g GAE/100g DM).

\subsection{Total Monomeric Anthocyanin Determination (TMA)}

Monomeric anthocyanins were measured by the pH-differential method, which relies on the structural transformation of the anthocyanin chromophore as a function of $\mathrm{pH}$, which can be measured using optical spectroscopy [20]. The appropriate dilutions of each sample were prepared, once with potassium chloride buffer at $0.025 \mathrm{M}$ (pH 1.0) and the other with sodium acetate buffer at 0.4 $\mathrm{M}$ (pH 4.5). The dilutions were equilibrated for $15 \mathrm{~min}$. The absorbance of each dilution was measured at the $\lambda_{\text {vis-max }}$ and at $700 \mathrm{~nm}$ against a blank cell filled with distilled water. The absorbance (A) of the diluted sample was calculated as follows: $\mathrm{A}=\left(\mathrm{A}_{\text {2vis-max }}-\mathrm{A}_{700}\right)_{\mathrm{pH} 1}-$ $\left(\mathrm{A}_{\text {ivis-max }}-\mathrm{A}_{700}\right)_{\mathrm{pH} 4.5}$. The monomeric anthocyanin pigment (MAP) concentration in the original sample was calculated using the following formula: $\operatorname{MAP}_{(\mathrm{mg} / \mathrm{L})}=(\mathrm{A} \times$ $\mathrm{MW} \times \mathrm{DF} \times 1000) /(\mathrm{molA} \times \mathrm{L}) . \mathrm{MW}$ and molA are the molecular weight and the molar absorptivity, respectively of the pigment cyanidin-3-glucoside used as reference; MW $=449.2 \mathrm{~g} /$ mole and molA $=26,900 \mathrm{mg}^{-1} \cdot \mathrm{L}^{-1} \cdot \mathrm{cm}^{-1}$. DF is the dilution factor used during the analysis. Milligrams of Monomeric Anthocyanin per liter of extract (mg/L) were then transformed into Total Monomeric 
Anthocyanin yield (TMA) which is milligrams per 100 grams of grape dry matter (mg/100g DM).

\subsection{Determination of Tannin Concentration (TC)}

Total tannin content $(\mathrm{g} / \mathrm{L})$ was determined according to Ribérau-Gayon et al. 1998 [21]. $2 \mathrm{~mL}$ of 1:50 diluted sample and $6 \mathrm{~mL}$ of $12 \mathrm{~N} \mathrm{HCl}$ were mixed and heated in a water bath for $30 \mathrm{~min}$. Following the rapid cooling, 1 $\mathrm{mL}$ of ethanol was added to the mixture, and the resulting absorbance at $550 \mathrm{~nm}$ was measured.

\subsection{Antioxidant and Antiradical Assays}

\subsubsection{Total Antioxidant Capacity (AC)}

The total antioxidant activity of the extracts was determined by the phosphomolybdenum reduction assay [22]. The basic principle of the method is the formation of a green phosphate Mo (V) complex at acidic $\mathrm{pH}$. The extracts reduce Mo (VI) to Mo (V). Diluted extracts (500 $\mathrm{mg} / \mathrm{L})$ were mixed with the reagent solution $(0.6 \mathrm{M}$ sulfuric acid, $28 \mathrm{mM}$ sodium phosphate and $4 \mathrm{mM}$ ammonium molybdate). The samples were incubated at $90^{\circ} \mathrm{C}$ for 90 minutes and the absorbance of the solution was measured at $695 \mathrm{~nm}$. The antioxidant activity is expressed as mg of Ascorbic Acid Equivalent per Liter (mg $\mathrm{AAE} / \mathrm{L})$.

\subsubsection{Antiradical Activity (AA)}

According to Gyamfi et al. 1999 [23] and Kallithraka et al. 2005 [24], the free radical scavenging activity was measured by the capacity of the phenolic compounds contained in the samples to reduce DPPH (2,2-diphenylpicrylhydrazyl), a stable free radical. The antiradical activity of extracts was examined by comparison to those of known antioxidants such as butylhydroxytoluene (BHT) (a synthetic antioxidant) and resveratrol (a natural antioxidant) by DPPH. $50 \mu \mathrm{L}$ of diluted extracts or positive control (BHT and resveratrol) $(50 \mu \mathrm{g} / \mathrm{mL})$ were added to $450 \mu \mathrm{L}$ of Tris- $\mathrm{HCl}$ buffer solution $(50 \mathrm{mM}, \mathrm{pH}$ 7.4). $1.5 \mathrm{~mL}$ of DPPH Solution $(0.1 \mathrm{mM})$ were added to the mixture. Absorbance at $517 \mathrm{~nm}$ was measured after 30 min of incubation at room temperature using pure Methanol as a blank. The inhibition percentage of the DPPH free radical is calculated as follows: Inhibition Percentage $=[($ absorbance of negative control - absorbance of sample)/absorbance of negative control] $\times 100$. The free radical scavenging activity of Cabernet Sauvignon grape byproducts extracts was evaluated by the decrease in the peak area of the DPPH radical which exhibits a deep purple color with maximum absorption at 517 $\mathrm{nm}$. Antioxidant molecules can quench DPPH free radicals, resulting in discoloration of DPPH because of their conversion into a colorless product.

\subsection{Experimental Design}

A rotatable central composite $\left(2^{2}+\right.$ star $)$ design was created to evaluate the main impact of two factors in 12 runs. The effects of time and temperature on the extraction of TPC, FC, TC and TMA contents from powdered grape pomace, so as on the bioactivity of the extracts represented by the AA and AC were studied. The same design was used for the extraction process from unmilled and milled grape pomace. Temperature values varied between $50^{\circ} \mathrm{C}$ and $90^{\circ} \mathrm{C}$ and time between 30 and 150 minutes. Time and temperature independent variables were coded at five levels $(-\alpha,-1,0,1, \alpha)$ resulting in an experimental design of twelve experimental points including four repetitions of the measurements at the center of the experimental design. Considering two parameters and a response, experimental data were fitted to obtain a second-degree regression equation of the form:

$$
\mathrm{Y}=\beta_{0}+\beta_{1} \mathrm{~T}+\beta_{2} \mathrm{t}+\beta_{12} \mathrm{~T} \cdot \mathrm{t}+\beta_{11} \mathrm{~T}^{2}+\beta_{22} \mathrm{t}^{2}
$$

where $\mathrm{Y}$ is the predicted response parameter, $\mathrm{t}$ is the extraction time and $\mathrm{T}$ the temperature, $\beta_{0}$ is the mean value of response at the central point of the experiment; $\beta_{1}$ and $\beta_{2}$ are the linear coefficients, $\beta_{11}$ and $\beta_{22}$ the quadratic coefficients and $\beta_{12}$ the interaction coefficient. Experimental design and statistical treatment of the results were performed using STATGRAPHICS Plus 4.0 for Windows.

\subsection{HPLC Analyses}

Phenolic compounds analyses of the extracts prepared from grape pomace were performed by high-performance liquid chromatography (HPLC). Prior to analytical chromatography, samples and standards were purified by filtration through $0.2 \mu \mathrm{m}$ syringe filters. A liquid chromatography-KNAUER apparatus coupled to a diode array detector was employed. Analyses were performed on a Spherisorb ODS-2 (5 mm, $250 * 4.6 \mathrm{~mm})$ column, at a flow rate of $1 \mathrm{~mL} \cdot \mathrm{min}^{-1}$, using a $20 \mu \mathrm{L}$ injection volume, and detection at $280 \mathrm{~nm}$ and $320 \mathrm{~nm}$. Eluent A was $2 \%$ aqueous Formic acid and eluent B was composed of: $69 \%$ Methanol $(\mathrm{MeOH}), 29 \%$ HPLC water and 2\% Formic acid. Identification was based on comparing retention times of the peaks detected with those of original compounds, and on UV-Vis on-line spectral data. Quantification was accomplished using the phenolic standards solutions. Results were expressed as $\mathrm{mg} / \mathrm{mL}$ of grape pomace extracted volume [25].

\section{Results and Discussion}

\subsection{Experimental Design}

Response Surface Methodology (RSM) was used to determine the adequate time and temperature for the opti- 
mization of TPC, FC, TMA, TC, AA and AC from milled and unmilled grape pomace. For milled pomace, TPC and FC ranged from 0.7 to $1.4 \mathrm{~g} \mathrm{GAE} / 100 \mathrm{~g} \mathrm{DM}$, TMA from 10.8 to $18.7 \mathrm{mg} / 100 \mathrm{~g} \mathrm{DM}$, TC from 0.5 to $2.9 \mathrm{~g} / \mathrm{L}$, AA from 22.5 to $34.5 \%$, and AC from 391.2 to $487.4 \mathrm{mg}$ AAE/L. For unmilled pomace, TPC ranged from 0.2 to $2 \mathrm{~g} \mathrm{GAE} / 100 \mathrm{~g} \mathrm{DM}$, FC 0.2 to $1.9 \mathrm{~g} \mathrm{GAE} /$ $100 \mathrm{~g}$ DM, TMA from 20.9 to $35.4 \mathrm{mg} / 100 \mathrm{~g} \mathrm{DM}$, TC from 0.7 to $3.3 \mathrm{~g} / \mathrm{L}$, AA from 25.6 to $38 \%$, and AC from 290 to $613.2 \mathrm{mg} \mathrm{AAE} / \mathrm{L}$.

\subsection{Experimental Modelization and Statistics}

Statistical analyses showed that response values fit best the second order polynomial equations. The coefficients of regression $\mathrm{R}^{2}$ were calculated by the analysis of the predicted values obtained by the regression models. A good agreement of the experimental results with the corresponding models is shown by satisfactory levels of adequacy implying a reasonable correlation between observed and predicted values (Table 1 ).

\subsection{Effect of the Extraction Parameters on TPC and FC}

Response surface plots (Figures 1 and 2) give by their shapes data about the effect of the experimental parameters. For milled pomace, TPC (Figure 1(a)) and FC (Figure 1(b)) increase with temperature increase to reach their maximal yields at $98^{\circ} \mathrm{C}$, while they decrease when incubation time increases with a 5 minutes optimal value. The phenolic compounds heat-induced extraction effi- ciency has been reported by many authors to boost the mass transfer, diminish the surface tension as well as the viscosity and solubilize the solutes [26,27]. However the oxidation/degradation of the extracted phenolics occurred as well beyond a certain temperature limit as it was suggested by different authors (ranging between $50^{\circ} \mathrm{C}$ and $\left.60^{\circ} \mathrm{C}[16,28]\right)$. Hereby, we highlight the dependence of the temperature to the duration of the extraction process, thus emphasizing the coupled effect of time and temperature. Concerning this specific issue literature reviews contain several experimental conditions such as long $[9,17,29-31]$ or short extraction times $[17,32,33]$. Our results show that it is possible to elevate the extraction temperature if the extraction time is reduced. In other terms, regarding the quantity, an important good TPC (1.65 g GAE/100g DM) and FC (1.6 g GAE/100g DM) content can be obtained by accelerating the aqueous extraction process by heat. In concordance with our findings, Sheng et al. 2013 optimized flavonoids extraction from Flos Populi at $94.66^{\circ} \mathrm{C}$ [34]. The optimization of aqueous phenolic compounds extraction from milled grape pomace at moderate temperatures and relatively long periods of time [15], was followed by the investigation of the potential capacity of transition to higher temperatures and shorter periods of time in the aim of reducing the overall cost of the process. The optimal conditions maximizing TPC yield, previously found by Rajha et al. 2013 in aqueous solution [15] were $47^{\circ} \mathrm{C}$ and 30 hours to obtain $0.7 \mathrm{~g}$ GAE/100g DM. Herein, we obtained $1.65 \mathrm{~g} \mathrm{GAE} / 100 \mathrm{~g} \mathrm{DM}$ at $98^{\circ} \mathrm{C}$ after 5 minutes. Hence, we doubled the quantity of TPC by doubling the

Table 1. Second order polynomial equations relating response variables to test variables for the unmilled and milled samples. $T$ is the milling time and the temperature. $R^{2}$ the coefficients of regression are shown for each equation.

\begin{tabular}{|c|c|c|}
\hline & & Regression equations \\
\hline \multirow{4}{*}{$\begin{array}{l}\text { Unmilled } \\
\text { samples }\end{array}$} & TPC & $\mathrm{TPC}=2.49638-0.0529507 \mathrm{t}-0.0202912 \mathrm{~T}+0.000321827 \mathrm{t}^{2}+0.00001762 \mathrm{~T}^{2}+0.000290734 \mathrm{t}\left(\mathrm{R}^{2}=83.5 \%\right)$ \\
\hline & TMA & $\mathrm{TMA}=-40.409+1.51755 \mathrm{t}+0.336676 \mathrm{~T}-0.0069981 \mathrm{t}^{2}-0.000455635 \mathrm{~T}^{2}-0.0041903 \mathrm{tT}\left(\mathrm{R}^{2}=91.5 \%\right)$ \\
\hline & AA & $\mathrm{AA}=12.3113+0.610053 \mathrm{t}+0.130909 \mathrm{~T}-0.00513862 \mathrm{t}^{2}-0.000223949 \mathrm{~T}^{2}-0.000901667 \mathrm{tT}\left(\mathrm{R}^{2}=96.7 \%\right)$ \\
\hline & AC & $A C=-834.409+35.8958 t+2.40927 T-0.240988 t^{2}-0.00371678 T^{2}-0.0204657 t T\left(R^{2}=65.5 \%\right)$ \\
\hline \multirow{5}{*}{$\begin{array}{c}\text { Milled } \\
\text { samples }\end{array}$} & TPC & $\mathrm{TPC}=0.916804-0.0122503 \mathrm{t}-0.000485086 \mathrm{~T}+0.000203125 \mathrm{t}^{2}+0.000015625 \mathrm{~T}^{2}-0.0000416667 \mathrm{tT}\left(\mathrm{R}^{2}=85.2 \%\right)$ \\
\hline & FC & $\mathrm{FC}=0.916804-0.0122503 \mathrm{t}-0.000485086 \mathrm{~T}+0.000203125 \mathrm{t}^{2}+0.000015625 \mathrm{~T}^{2}-0.0000416667 \mathrm{tT}\left(\mathrm{R}^{2}=85.2 \%\right)$ \\
\hline & TC & $\mathrm{TC}=-2.13786+0.0446507 \mathrm{t}+0.026491 \mathrm{~T}+0.0000468751 \mathrm{t}^{2}-0.0000364582 \mathrm{~T}^{2}-0.000270833 \mathrm{t}\left(\mathrm{R}^{2}=76.5 \%\right)$ \\
\hline & AA & $\mathrm{AA}=48.0791-0.274418 \mathrm{t}-0.2022 \mathrm{~T}+0.000609375 \mathrm{t}^{2}+0.000859374 \mathrm{~T}^{2}+0.0006875 \mathrm{tT}\left(\mathrm{R}^{2}=79 \%\right)$ \\
\hline & AC & $\mathrm{AC}=377.083+3.05453 \mathrm{t}+0.188267 \mathrm{~T}-0.0272187 \mathrm{t}^{2}+0.00182291 \mathrm{~T}^{2}-0.00545833 \mathrm{tT}\left(\mathrm{R}^{2}=87 \%\right)$ \\
\hline
\end{tabular}




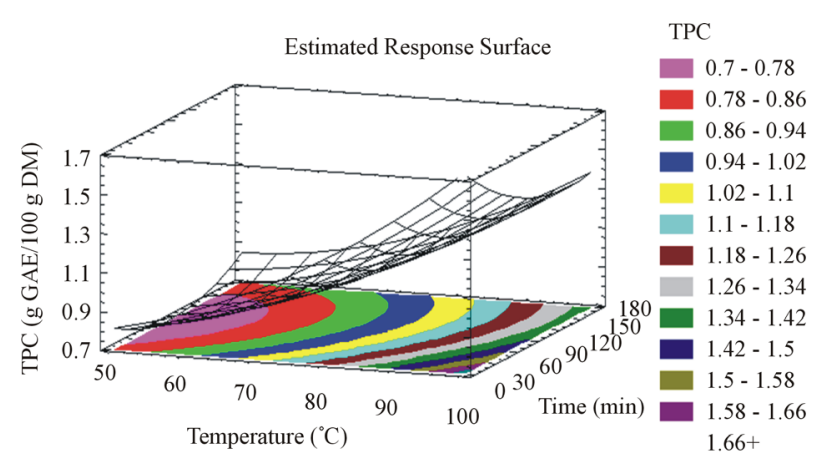

(a)

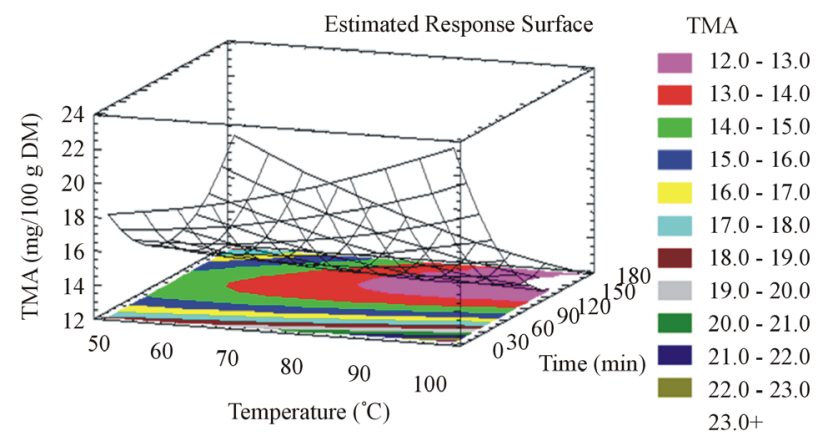

(c)

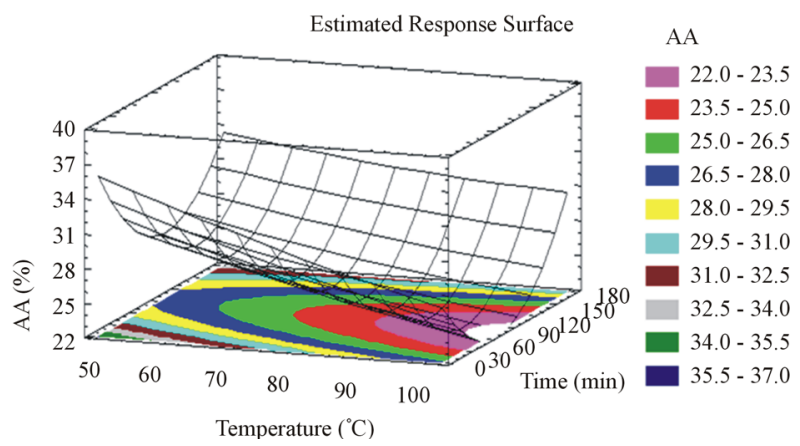

(e)

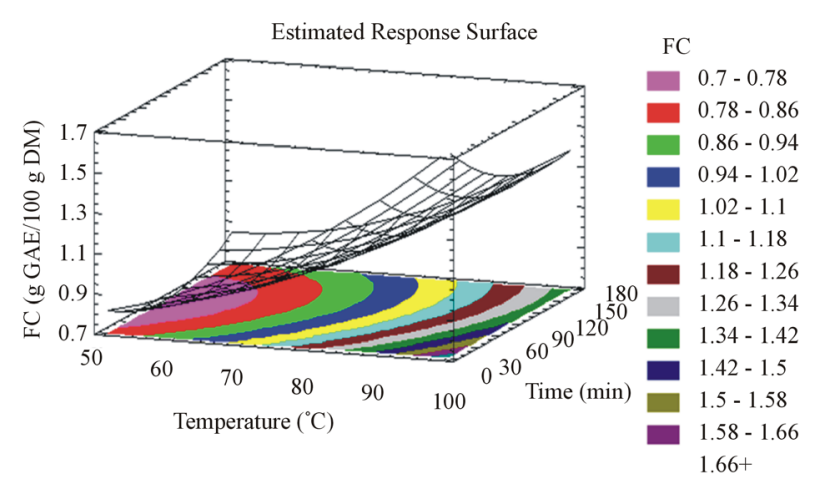

(b)

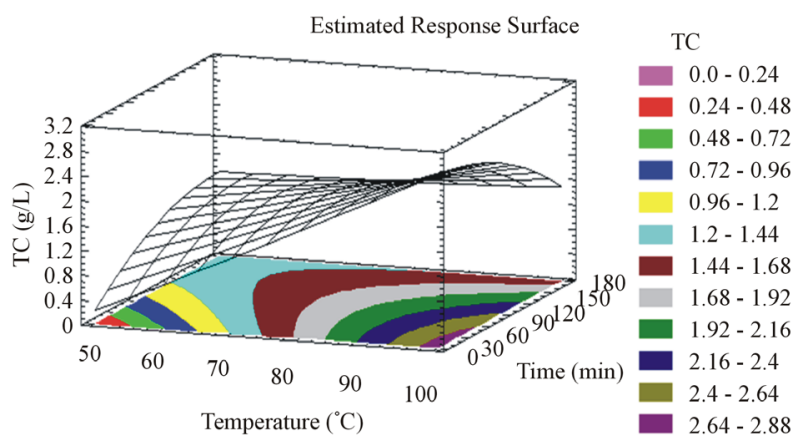

(d)

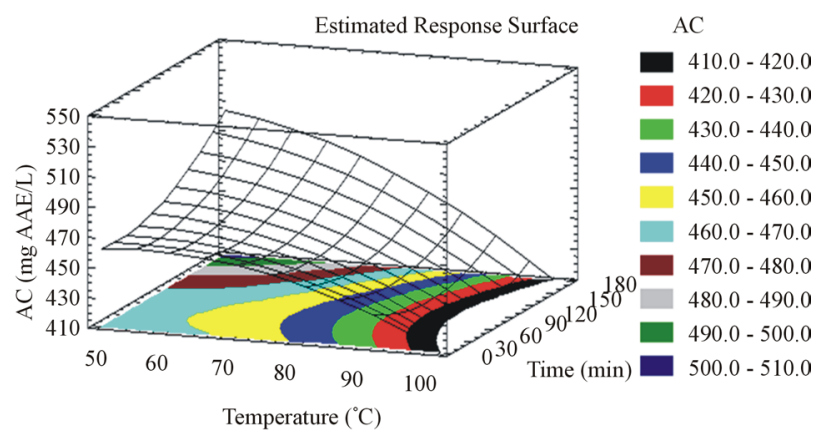

(f)

Figure 1. Phenolic compounds yield, flavonoid content, anthocyanin content, tannin content, antiradical activity and antioxidant capacity surface plots for milled samples. The three-dimensional graphs were plotted between two independent variables (time and temperature).

extraction temperature and reducing the duration of the process by 360 times. For unmilled pomace, TPC (Figure 2(a)) and FC (Figure 2(b)) increase with both time and temperature to reach their maximal yields at $98^{\circ} \mathrm{C}$ during 175 minutes of incubation. The difference of the parameters effect on both raw materials demonstrates the importance of the particle size together with time and temperature. The latter seems to increase molecular movement and enhance the extraction process with both milled and unmilled grape pomace. However, our results showed that shorter time is needed when pomace is milled in order to accelerate TPC and FC extractions. Slinkard and Singleton [18] explain this phenomenon by the increased accessibility to the superficial area of the milled product, thus enhancing the mass transfer.

\subsection{Effect of the Extraction Parameters on TMA}

For milled and unmilled pomace, TMA (Figures 1(c) and 2(c)) augments with temperature elevation to attain its optimal yield at $98^{\circ} \mathrm{C}$, at an optimal incubation time of 5 minutes. In contrastto this observation, Lapornik et al. [30] showed a positive effect of time. This variation is probably due to the lower temperature they adopted in their study. Moreover, Jackman et al. 1987 [35] stated temperature, as one of the main anthocyanins degrada- 


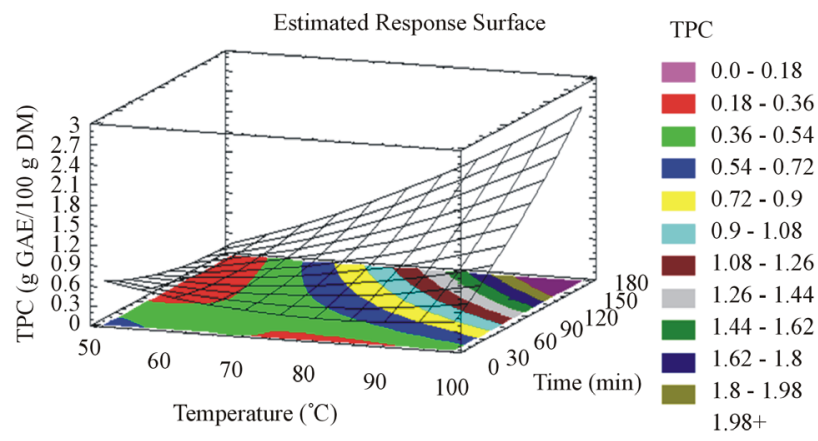

(a)

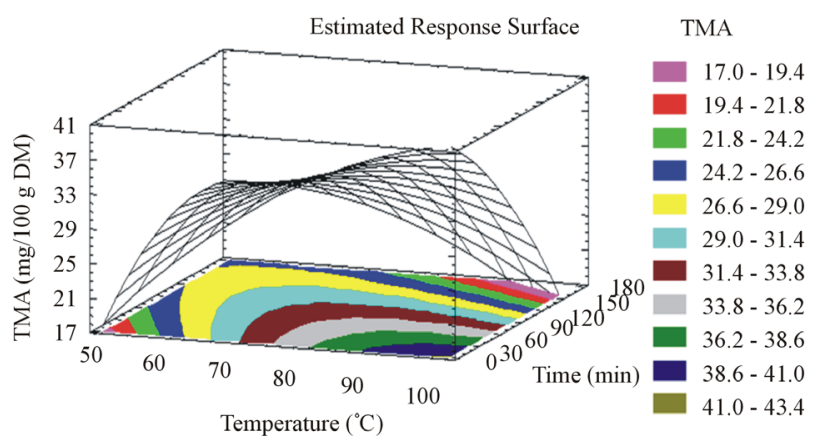

(c)

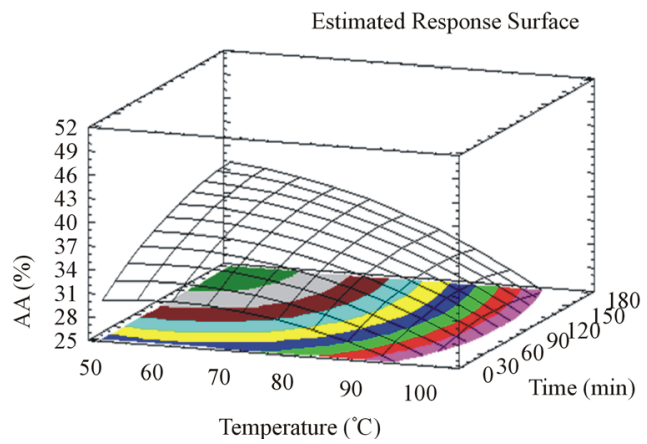

(e)

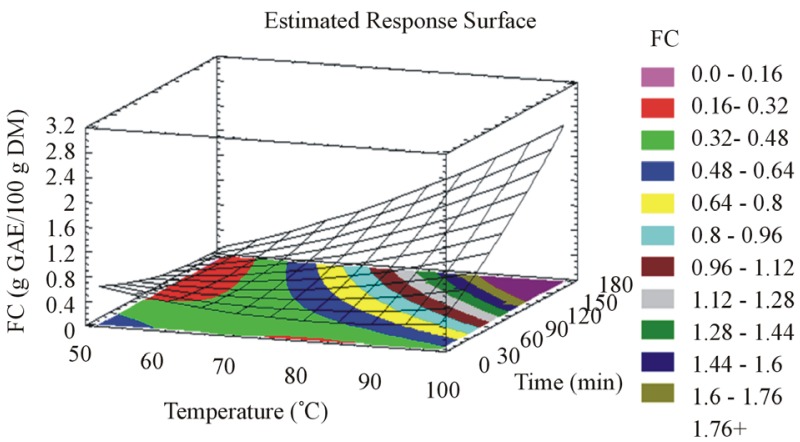

(b)

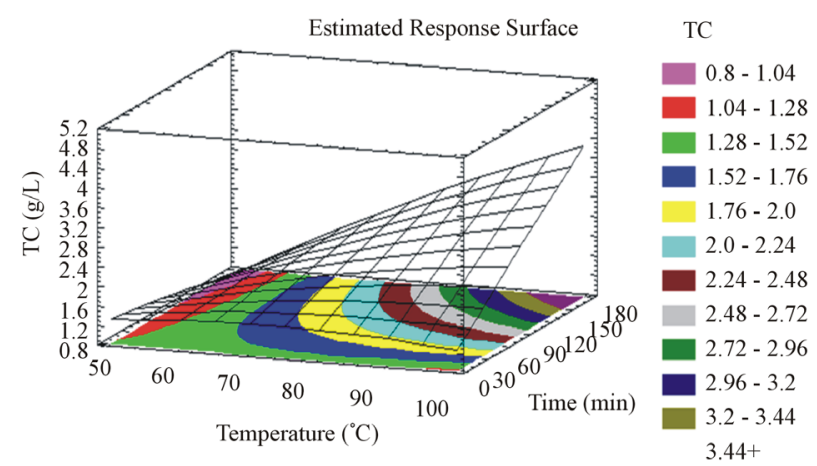

(d)

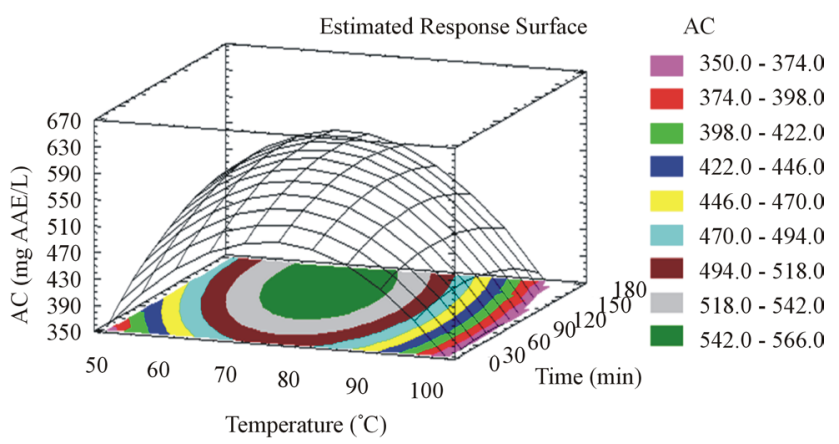

(f)

Figure 2. Phenolic compounds yield, flavonoid content, anthocyanin content, tannin content, antiradical activity and antioxidant capacity surface plots for unmilled samples. The three-dimensional graphs were plotted between two independent variables (time and temperature).

tion causes. In this work, degradation kinetics was not triggered by the use of a high temperature because of the short exposure time. The temperature elevation has been shown to diminish anthocyanin extraction time [28]. Particle size reduction showed no effect on TMA extraction parameters but on the optimal anthocyanin yield which was higher for the unmilled $(41 \mathrm{mg} / 100 \mathrm{~g} \mathrm{DM})$, rather than milled pomace (22.5 mg/100g DM).

\subsection{Effect of the Extraction Parameters on TC}

For milled pomace, TC (Figure 1(d)) increases when temperature increases and diminishes in function of time to attain its optimal value $(2.7 \mathrm{~g} / \mathrm{L})$ at $98^{\circ} \mathrm{C}$ after $5 \mathrm{mi}-$ nutes. For unmilled pomace, TC (Figure 2(d)) augments with time and temperature elevation to attain its optimal value $(4 \mathrm{~g} / \mathrm{L})$ at $98^{\circ} \mathrm{C}$ after 175 minutes. In agreement with our results, Connolly in 1993 [36] patented tannin extraction from bark to be preferably done between 90 and $100^{\circ} \mathrm{C}$. Particle size reduction accelerated the tannin extraction from grape pomace, however and similarly to TMA, the optimal tannin yield was higher for the unmilled $(4 \mathrm{~g} / \mathrm{L})$, rather than milled pomace $(2.7 \mathrm{~g} / \mathrm{L})$. TPC, FC and TC are simultaneously extracted from unmilled pomace with the same optimal parameters, while for milled pomace all the studied compounds were extracted 
at the same conditions.

\subsection{Effect of the Extraction Parameters on AA and $\mathrm{AC}$}

For milled pomace, AA (Figure 1(e)) diminishes when time and temperature increase. The optimal AA is $36.8 \%$ obtained at $42^{\circ} \mathrm{C}$ after 5 minutes incubation time. For unmilled pomace, AA (Figure 2(e)) diminishes when temperature increases but augments with time increase. The optimal AA is $38.3 \%$ obtained at $44^{\circ} \mathrm{C}$ after 175 minutes. Unmilled pomace require higher extraction times compared to milled pomace, to produce the same AA. This could be related to the phenolic compounds diversity and even quantity obtained from both unmilled and milled pomace. In our previous study [15], we optimized the AA from milled pomace and obtained $41.15 \%$ at $30^{\circ} \mathrm{C}$ after 20 hours of aqueous solid liquid extraction. Our new results show a gain of almost 20 hours by elevating the temperature from $30^{\circ} \mathrm{C}$ to $42^{\circ} \mathrm{C}$, without losing a significant percentage of the AA. As for the AC, it diminishes when temperature increases but augments with time increase for milled samples (Figure 1(f)). The optimal AC for milled pomace is found at $42^{\circ} \mathrm{C}$ after 175 minutes. Unmilled pomace extracts show an AC that augments with temperature elevation up to $69^{\circ} \mathrm{C}$ (optimal temperature) then diminishes (Figure 2(f)). The same tendency is shown for time, the optimal value is $135 \mathrm{mi}$ nutes. However unmilled pomace extracts also show a slight insignificantly higher AC (562 mg AAE/L) than milled pomace (506 mg AAE/L). For both milled and unmilled extracts the optimizations of AA and AC gave almost the same values of the responses at different time and temperature combinations.

\subsection{Multiple Response Optimization}

The graphics of the outlines superposition (Figures 3 and 4) show by the black spots, the optimal experimental parameters for the simultaneous optimization of all the responses together (TPC, FC, TMA, TC, AA and AC), for milled and unmilled pomace extracts respectively. The optimal conditions maximizing TPC and AA, in our previous work [15] were $37^{\circ} \mathrm{C}$ and 28 hours to obtain $0.52 \mathrm{~g} \mathrm{GAE} / 100 \mathrm{~g} \mathrm{DM}$ and $23 \%$ respectively. Herein, the optimal extraction conditions obtained for milled pomace were $88^{\circ} \mathrm{C}$ and 5 minutes to acquire a TPC and FC of 1.4 g GAE/100g DM, a TMA of $21 \mathrm{mg} / 100 \mathrm{~g}$ DM, a TC of $2.2 \mathrm{~g} / \mathrm{L}$, an AA of $28 \%$ and an AC of $433 \mathrm{mg} \mathrm{AAE} / \mathrm{L}$. In sum, we have succeeded through elevating the extraction temperature from $37^{\circ} \mathrm{C}$ to $88^{\circ} \mathrm{C}$, to lower the extraction time from 28 hours to 5 minutes and to elevate by 2.7 times the TPC yield without affecting the bioactivity of the extracts, in terms of antiradical and antioxidant activ-

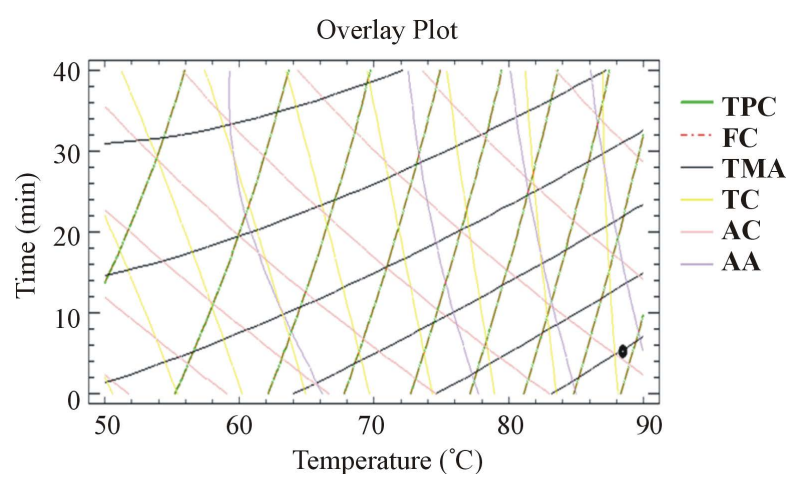

Figure 3. Desirability analysis. Superposition plots, showing the best experimental parameters that maximize all the responses for milled samples. The black spot shows the optimum for all the responses.

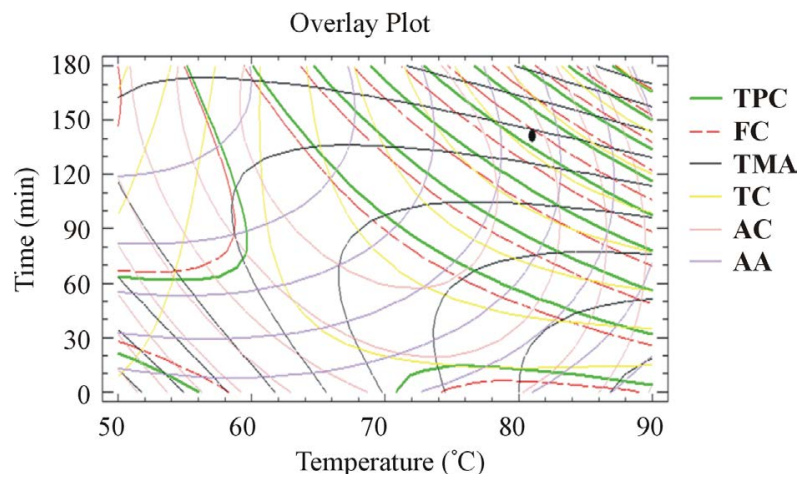

Figure 4. Desirability analysis. Superposition plots, showing the best experimental parameters that maximize all the responses for unmilled samples. The black spot shows the optimum for all the responses.

ities.

Unmilled pomace extraction optimization parameters are: $81^{\circ} \mathrm{C}$ and 140 minutes, to obtain a TPC of $1.1 \mathrm{~g}$ GAE/100g DM, a FC of $1 \mathrm{~g}$ GAE/100g DM, a TMA of $27.3 \mathrm{mg} / 100 \mathrm{~g} \mathrm{DM}$, a TC of $2.5 \mathrm{~g} / \mathrm{L}$, an AA of $32 \%$ and $\mathrm{AC}$ of $524 \mathrm{mg} \mathrm{AAE} / \mathrm{L}$. The difference between the response values (TPC, FC, TMA, TC, AA and AC) for milled and unmilled pomace extracts are almost not significant.

We can therefore consider that to obtain the same phenolic quantity and bioactivity of the milled and unmilled pomace extracts, the primordial experimental parameter to vary is time for almost the same extraction temperature.

\subsection{HPLC Determination of Molecular Distribution in Extract}

HPLC analyses were done for both the optimums previously found for milled and unmilled pomace extracts in order to study the possibility to substitute the milling process by simply lengthening the extraction time. 


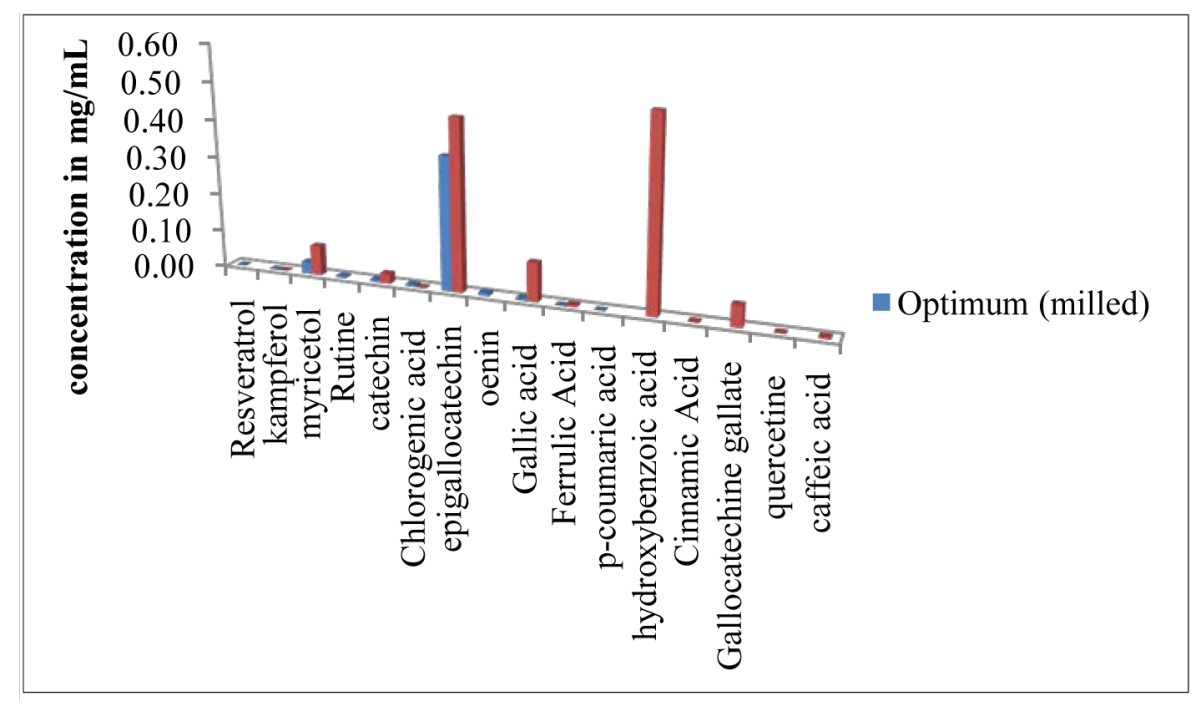

Figure 5. Phenolic content of the optimums determined by HPLC.

Figure 5 shows the concentration and diversity of the phenolic compounds found at the optimal points for milled and unmilled pomace extracts. In terms of diversity, milled pomace extracts containted 11 different compounds (Resveratrol, kaempferol, myricetol, rutin, catechin, epigallocatechin, oenin, gallic, ferrulic, coumaric and chlorogenic acids) while unmilled pomace extracts had 12 (Kaempferol, myricetol, catechin, epigallocatechin, gallocatechin gallate, quercetin, gallic, ferrulic, hydrobenzoic cinnamic, caffeic and chlorogenic acids). The phenolic content of the extracts was different, each contained several compounds at different quantities. In a previous work [37], we showed that with the same extraction method, solvent and raw material, HPLC chromatograms were different at different extraction temperatures. Herein, we show that extracting at the same temperature, when using the same raw material, is not sufficient to have the same phenolic diversity and quantity even if the extracts have the same bioactivity and total phenolic quantity. Phenolic diversity also depends on the extraction time and particle size, which allow the extraction of certain compounds at the expense of others, or simply enhances their availabiliy.

Despite the different HPLC prints for the optimum parameters for milled and unmilled pomace the overall bioactivity of the mixtures remained the same. Therefore if we are looking for a better quality mixture independently of a certain molecular targeting we can easily substitute the milled pomace with the unmilled one, by enhancing the extraction time.

\section{Conclusion}

This work permitted the enhancement of phenolic compounds extraction from grape byproducts by elevating the temperature of the aqueous solution used in the extraction process, without affecting the bioactivity of the extracts. Characterization through physiochemical and HPLC analyses confirmed the possibility of substituting the grape byproducts milling process by an unmilled one especially when incubating the extracts for longer times in aqueous solutions and at high temperatures.

\section{Acknowledgements}

The Research Council of Saint Joseph University of Beirut funded this work (Project FS54). We are grateful to Joseph Yaghi for technical assistance and to the society Château KSARA for providing the grape pomace.

\section{REFERENCES}

[1] G. Spigno, T. Pizzorno and D. M. De Faveri, "Cellulose and Hemicelluloses Recovery from Grape Stalks," Bioresource Technology, Vol. 99, No. 10, 2008, pp. 43294337. http://dx.doi.org/10.1016/j.biortech.2007.08.044

[2] S. O. Prozil, D. V. Evtuguin and L. P. C. Lopes, "Chemical Composition of Grape Stalks of Vitis vinifera L. from Red Grape Pomaces,” Industrial Crops Products, Vol. 35, No. 1, 2012, pp. 178-184. http://dx.doi.org/10.1016/j.indcrop.2011.06.035

[3] A. J. Shrikhande, "Wine By-Products with Health Benefits,” Food Research International, Vol. 33, No. 6, 2000, pp. 469-474.

http://dx.doi.org/10.1016/S0963-9969(00)00071-5

[4] M. Careri, C. Corradini, L. Elviri, I. Nicoletti and I. Zagnoni, "Direct HPLC Analysis of Quercetin and TransResveratrol in Red Wine, Grape, and Winemaking Byproducts," Journal of Agriculture and Food Chemistry, Vol. 51, No. 18, 2003, pp. 5226-5231. http://dx.doi.org/10.1021/jf034149g

[5] V. Amico, E. M. Napoli, A. Renda, G. Ruberto, C. Spa- 
tafora and C. Tringali, "Constituents of Grape Pomace from the Sicilian Cultivar 'Nerello Mascalese'," Food Chemistry, Vol. 88, No. 4, 2004, pp. 599-607.

http://dx.doi.org/10.1016/j.foodchem.2004.02.022

[6] G. Ruberto, A. Renda, C. Daquino, V. Amico, C. Spatafora, C. Tringali and N. De Tommasi, "Polyphenol Constituents and Antioxidant Activity of Grape Pomace Extracts from Five Sicilian Red Grape Cultivars," Food Chemistry, Vol. 100, No. 1, 2007, pp. 203-210. http://dx.doi.org/10.1016/j.foodchem.2005.09.041

[7] V. K. Joshi and M. P. Devi, "Resveratrol: Importance, Role, Contents in Wine and Factors Influencing Its Production," Proceedings of the National Academy of Sciences India. Section B, Vol. 79, No. 3, 2009, pp. 212-226.

[8] Communication from the Commission to the Council and the European Parliament (CCE), "Towards a Sustainable European Wine Sector,” Brussels, 2006.

[9] G. Spigno and D. M. De Faveri, “Antioxidants from Grape Stalks and Marc: Influence of Extraction Procedure on Yield, Purity and Antioxidant Power of the Extracts," Journal of Food Engineering, Vol. 78, No. 3, 2007, pp. 793-801. http://dx.doi.org/10.1016/j.jfoodeng.2005.11.020

[10] L. Ping, N. Brosse, L. Chrusciel, P. Navarrete and A. Pizzi, "Extraction of Condensed Tannins from Grape Pomace for Use as Wood Adhesives," Industrial Crops and Products, Vol. 33, No. 1, 2011, pp. 253-257. http://dx.doi.org/10.1016/j.indcrop.2010.10.007

[11] L. Ping, A. Pizzi, Z. D. Guo and N. Brosse, "Condensed Tannins Extraction from Grape Pomace: Characterization and Utilization as Wood Adhesives for Wood Particleboard," Industrial Crops and Products, Vol. 34, No. 1, 2011, pp. 907-914. http://dx.doi.org/10.1016/j.indcrop.2011.02.009

[12] E. Barzana, D. Rubio, R. I. Santamaria, O. Garcia-Correa, F. Garcia, V. E. Ridaura-Sanz and A. López-Munguía, "Enzyme-mediated Solvent Extraction of Carotenoids from Marygold Flower (Tagetes erecta)," Journal of Agricultural and Food Chemistry, Vol. 50, No. 16, 2002, pp. 4491-4496. http://dx.doi.org/10.1021/jf025550q

[13] G. E. P. Box and K. B. Wilson, "On the Experimental Attainment of Optimum Conditions,” Journal of the Royal Statistical Society, Vol. 13, No. 1, 1951, pp. 1-45.

[14] R. H. Myers and D. C. Montgomery, "Response Surface Methodology: Process and Product Optimization Using Designed Experiments,” 2nd Edition, Wiley, New York, 2002.

[15] H. N. Rajha, N. El Darra, E. Vorobiev, N. Louka and R. G. Maroun, “An Environment Friendly, Low-Cost Extraction Process of Phenolic Compounds from Grape Byproducts. Optimization by Multi-Response Surface Methodology," Food and Nutrition Sciences, Vol. 4, No. 6, 2013, pp. 650-659.

http://dx.doi.org/10.4236/fns.2013.46084

[16] G. Spigno, L. Tramelli and M. De Faveri, "Effects of Extraction Time, Temperature and Solvent on Concentration and Antioxidant Activity of Grape Marc Phenolics,” Journal of Food Engineering, Vol. 81, No. 1, 2007, pp.
200-208.

http://dx.doi.org/10.1016/j.jfoodeng.2006.10.021

[17] M. Pinelo, M. Rubilar, M. Jerez, J. Sineiro and M. J. Nuñez, "Effect of Solvent, Temperature, and Solvent-toSolid Ratio on the Total Phenolic Content and Antiradical Activity of Extracts from Different Components of Grape Pomace," Journal of Agricultural and Food Chemistry, Vol. 53, No. 6, 2005, pp. 2111-2117. http://dx.doi.org/10.1021/jf0488110

[18] K. Slinkard and V. L. Singleton, “Total Phenol Analysis: Automation and Comparison with Manual Methods," American Journal of Enology and Viticulture, Vol. 28, No. 1, 1977, pp. 49-55.

[19] M. A. Amerine and C. S. Ough, "Methods for Analysis of Musts and Wines,” Wiley, New York, 1980.

[20] M. M. Giusti and R. E. Wrolstad, "Characterization and Measurement of Anthocyanins by UV-Visible Spectroscopy," In: Current Protocols in Food Analytical Chemistry, John Wiley \& Sons, Inc., 2001. http://dx.doi.org/10.1002/0471142913.faf0102s00

[21] P. Ribéreau-Gayon, D. Dubourdieu and B. Donèche, “Traité d'œnologie, Tome 2,” 6th Edition, Chimie du Vin, Stabilisation et Traitements, Dunod, 1998.

[22] P. Preito, M. Pineda and M. Aguilar, "Spectrphotometric Quantitation of Antioxidant Capacity through the Formation of a Phosphomolybdenum Complex: Specific Application to the Determination of Vitamin E," Analytical Biochemistry, Vol. 269, No. 2, 1999, pp. 337-341. http://dx.doi.org/10.1006/abio.1999.4019

[23] M. A. Gyamfi, M. Yonamine and Y. Aniya, "Free Radical Scavenging Action of Medicinal Herbs from Ghana: Thonningiasanguinea on Experimentally-Induced Liver Injuries," General Pharmacology: The Vascular System, Vol. 32, No. 6, 1999, pp. 661-667.

http://dx.doi.org/10.1016/S0306-3623(98)00238-9

[24] S. Kallithraka, A. A.-A. Mohdaly, D. P. Makris and P. Kefalas, "Determination of Major Anthocyanin Pigments in Hellenic Native Grape Varieties (Vitis vinifera $s p$.): Association with Antiradical Activity," Journal of Food Composition and Analysis, Vol. 18, No. 5, 2005, pp. 375386. http://dx.doi.org/10.1016/j.jfca.2004.02.010

[25] P. Ho, T. A. Hogg and M. C. M. Silva, “Application of a Liquid Chromatography for the Determination of Phenolic Compounds and Furans in Fortified Wines," Food Chemistry, Vol. 64, No. 1, 1999, pp. 115-122. http://dx.doi.org/10.1016/S0308-8146(98)00115-0

[26] L. Ramos, E. M. Kristenson and U. A. T. Brinkman, "Current Use of Pressurised Liquid Extraction and Subcritical Water Extraction in Environmental Analysis," Journal of Chromatography A, Vol. 975, No. 1, 2002, pp. 3-29. http://dx.doi.org/10.1016/S0021-9673(02)01336-5

[27] B. E. Richter, "Extraction of Hydrocarbon Contamination from Soils Using Accelerated Solvent Extraction,” Journal of Chromatography A, Vol. 874, No. 2, 2000, pp. $217-224$ http://dx.doi.org/10.1016/S0021-9673(00)00073-X

[28] J. E. Cacace and G. Mazza, "Mass Transfer Process during Extraction of Phenolic Compounds from Milled Ber- 
ries,” Journal of Food Engineering, Vol. 59, No. 4, 2003, pp. 379-389. http://dx.doi.org/10.1016/S0260-8774(02)00497-1

[29] B. Pekić, V. Kovač, E. Alonso and E. Revilla, "Study of the Extraction of Proanthocyanidins from Grape Seeds," Food Chemistry, Vol. 61, No. 1-2, 1998, pp. 201-206. http://dx.doi.org/10.1016/S0308-8146(97)00128-3

[30] B. Lapornik, M. Prošek and A. Golc Wondra, "Comparison of Extracts Prepared from Plant By-Products Using Different Solvents and Extraction Time,” Journal of Food Engineering, Vol. 71, No. 2, 2005, pp. 214-222. http://dx.doi.org/10.1016/j.jfoodeng.2004.10.036

[31] G. K. Jayaprakasha, R. P. Singh and K. K. Sakariah, “Antioxidant Activity of Grape Seed (Vitis vinifera) Extracts on Peroxidation Models in Vitro," Food Chemistry, Vol. 73, No. 3, 2001, pp. 285-290. http://dx.doi.org/10.1016/S0308-8146(00)00298-3

[32] F. Bonilla, M. Mayen, J. Merida and M. Medina, "Extraction of Phenolic Compounds from Red Grape Marc for Use as Food Lipid Antioxidants," Food Chemistry, Vol. 66, No. 2, 1999, pp. 209-215. http://dx.doi.org/10.1016/S0308-8146(99)00046-1

[33] Y. Yilmaz and R. T. Toledo, “Oxygen Radical Absor- bance Capacities of Grape/Wine Industry By-Products and Effect of Solvent Type on Extraction of Grape Seed Polyphenols,” Journal of Food Composition and Analysis, Vol. 19, No. 1, 2006, pp. 41-48. http://dx.doi.org/10.1016/j.jfca.2004.10.009

[34] Z. L. Sheng, P. F. Wan, C. L. Dong and Y. H. Li, "Optimization of Total Flavonoids Content Extracted from Flospopuli Using Response Surface Methodology,” Industrial Crops and Products, Vol. 43, 2013, pp. 778-786.

[35] R. L. Jackman, R. Y. Yada, M. A. Tung and R. Speers, "Anthocyanins as Food Colorants-A Review," Journal of Food Biochemistry, Vol. 11, No. 3, 1987, pp. 201-247. http://dx.doi.org/10.1111/j.1745-4514.1987.tb00123.x

[36] D. L. Connolly, “Tannin Extraction,” US Patent No. 5 238 680, 1993.

[37] H. N. Rajha, N. El Darra, N. Louka, R. G. Maroun, W. Ziegler and H. Bochzelt, "Valorization of Industrial Waste Using Energy Saving Procedures. Phenolic Compounds Purification from Grape By-Products by Accelerated Solvent Extraction (ASE)," Proceedings of the International Conference on Renewable Energies for Developing Countries, Beirut, 28-29 November 2012, pp. 1-5.

\author{
Abbreviations \\ g: Gram \\ mL: Milliliter \\ mg: Milligram \\ A: Absorbance \\ UV: Ultraviolet \\ DM: Dry Matter \\ MeOH: Methanol \\ DF: Dilution Factor \\ HCL: Hydrochloride \\ TC: Tannin Content \\ FC: Flavonoid Content \\ AA: Antiradical Activity \\ AC: Total Antioxidant Capacity
}

TPC: Total Phenolic Content

TMA: Total Monomeric Anthocyanins

GAE: Gallic Acid Equivalent

AAE: Ascorbic Acid Equivalent

MW: Molecular Weight

molA: Molar Absorptivity

BHT: Butylhydroxytoluene

RSM: Response Surface Methodology

PCY: Phenolic Compounds Yield

PCC: Phenolic Compounds Concentration

DPPH: 2,2-Diphenyl-Picrylhydrazyl

MAP: The Monomeric Anthocyanin Pigment

HPLC: High Performance Liquid Chromatography 